\title{
Expression of DNA-dependent protein kinase in human granulocytes
}

\author{
Annahita SALLMYR ${ }^{1}$, Anna MILLER ${ }^{1,2}$, Aida GABDOULKHAKOVA ${ }^{1,2}$, Valentina SAFRONOVA ${ }^{1,2}$, \\ Gunnel HENRIKSSON ${ }^{1}$, Anders BREDBERG ${ }^{1, *}$ \\ ${ }^{1}$ Department of Medical Microbiology, Lund University, Malmo University Hospital, S-205 02 Malmo, Sweden. \\ ${ }^{2}$ Laboratory of Nerve Cell Biophysics, Institute of Cell Biophysics, Russian Academy of Sciences, Pushchino, Moscow region, \\ 142290 Russia.
}

\begin{abstract}
Human polymorphonuclear leukocytes (PMN) have been reported to completely lack of DNA-dependent protein kinase (DNA-PK) which is composed of Ku protein and the catalytic subunit DNA-PKcs, needed for nonhomologous end-joining (NHEJ) of DNA double-strand breaks. Promyelocytic HL-60 cells express a variant form of Ku resulting in enhanced radiation sensitivity. This raises the question if low efficiency of NHEJ, instrumental for the cellular repair of oxidative damage, is a normal characteristic of myeloid differentiation. Here we confirmed the complete lack of DNAPK in PMN protein extracts, and the expression of the truncated Ku86 variant form in HL-60. However, this degradation of DNA-PK was shown to be due to a DNA-PK-degrading protease in PMN and HL-60. In addition, by using a protease-resistant whole cell assay, both Ku86 and DNA-PKcs could be demonstrated in PMN, suggesting the previously reported absence in PMN of DNA-PK to be an artefact. The levels of Ku86 and DNA-PKcs were much reduced in PMN, as compared with that of the lymphocytes, whereas HL-60 displayed a markedly elevated DNA-PK concentration. In conclusion, our findings provide evidence of reduced, not depleted expression of DNA-PK during the mature stages of myeloid differentiation.
\end{abstract}

Keywords: DNA repair, nonhomologous end-joining, myeloid differentiation, Ku86 variant form.

\section{INTRODUCTION}

Human blood polymorphonuclear leukocytes $(\mathrm{PMN})^{1}$ have been reported to be deficient in DNA repair $[1,2]$, including the DNA-dependent protein kinase (DNA-PK) components of nonhomologous end-joining (NHEJ), i.e. both the DNA-binding Ku70/Ku86 heterodimer and the catalytic subunit (DNA-PKcs) [3-8]. It may seem a paradox, for a cell generating large quantities of reactive oxygen species (ROS) inducing potentially lethal doublestrand DNA breaks [9], to refrain from a DNA repair mechanism in response to this type of DNA damage. However, this might serve to increase cellular fitness, by directing cellular ATP to the main tasks of phagocytosis and secretion of anti-bacterial compounds in these terminally differentiated and non-dividing cells, with a life span as short as $6 \mathrm{~h}$ in peripheral blood and ending in apoptosis [10]. Numerous studies using the prototype promyelocytic leukemia HL-60 cell line, including cultures which are

${ }^{*}$ Correspondence: Anders BREDBERG

Tel: +46-40-337414, Fax: +46-40-336234;

E-mail: anders.bredberg@mikrobiol.mas.lu.se induced to differentiate towards mature PMN, have also revealed that DNA-PK alterations presumed to be causally linked to the enhanced gamma radiation sensitivity displayed by HL-60 [3, 11-15]. Recently, human acute myeloid leukemia (AML) chromosome translocation fusion products were shown to be able to down-regulate the expression of a set of DNA repair genes including DNA-PK [16]. Taken together, these data on PMN and pro-granulocytic cells indicate that down-regulation of NHEJ is a normal characteristic of myeloid differentiation.

We now confirm that although there was a complete lack of DNA-PK in PMN protein extracts, the presence of a DNA-PK-degrading protease in both PMN and HL-60 maybe responsible for the artefact. Our data suggest that the truncated Ku86 variant form demonstrated in HL-60 is induced by this protease, and that the Ku86 truncation reported to occur in human lymphocytes is caused by lowgrade contamination with PMN in PBMC preparations. Furthermore, using a protease-resistant whole cell assay, we verified the presence of Ku86 in PMN [8], and were able to demonstrate the presence of DNA-PKcs in PMN. However, the levels of both Ku86 and DNA-PKcs were 
much reduced in PMN when compared with that of the lymphocytes, and HL-60 displayed a markedly elevated DNA-PK concentration. In conclusion, our findings provide evidence of reduced expression of DNA-PK during the mature stages of myeloid differentiation.

\section{MATERIALS AND METHODS}

\section{Antibodies}

Antibodies used were as follows: anti-Ku86 (clone S10B1) (reactive with an N-terminal epitope) and anti-tubulin (DM1A) was from Oncogene; anti-Ku70 (SC-1486), anti-DNA-PKcs (SC-1552) and anti-actin from Santa Cruz Biotechnology; anti-DNA ligase IV (AHP554) and anti-caspase 3 (AHP476) from Serotec. Horse-radish peroxidase-conjugated secondary antibodies were from DAKO.

\section{Cells and culture conditions}

The HL-60, K562, U937 and NB-4 human leukaemia cell lines were gifts from Dr. Urban Gullberg, Department of Hematology, Lund University, and were split at least 3 times per week to be in exponential growth. HEp-2 was from the American Type Culture Collection (CCL23). These cultures were kept in RPMI 1640 medium containing L-glutamine and $10 \%$ fetal calf serum (20\% for HL-60). Peripheral blood mononuclear cells (PBMC) were isolated from human healthy donors using Lymphoprep density gradient (Nycomed). Polymorphonuclear leukocytes (PMN) were also isolated from freshly collected venous blood with Lymphoprep; the PMN were removed from the thin white layer on top of the erythrocyte pellet. Remaining red cells were then lysed before the PMN were finally recovered by 10 min centrifugation at $300 \mathrm{~g}$. The purity of PMN was at least $95 \%$ as determined by flow cytometry forward and side light scattering. Viability was determined with trypan blue (Sigma) and light microscopy.

\section{Western blot}

Cytoplasmic and nuclear protein extracts were prepared as described in detail elsewhere [17]. A mixture of protease inhibitors (Complete, Roche-Boehringer-Mannheim) was added at 10\% v/v to all buffers prior to extraction. SDS gels (7\% polyacrylamide trisacetate, except for the gradient 3-8\% gel used for DNA-PKcs analysis), SDS running buffer, transfer buffer, DTT reducing agent and sample buffer containing detergent were from Invitrogen. For Ku86 detection $10 \mu \mathrm{g}$ cytoplasmic and $5 \mu \mathrm{g}$ nuclear extract was used; for DNA-PKcs $50 \mu \mathrm{g}$ cytoplasmic and $25 \mu \mathrm{g}$ nuclear extract. A pre-stained size marker was included in each run. Enhanced chemiluminescence (ECL from Amersham-Pharmacia) and either X-ray film or a BioRad Personal Molecular Imager FX were used for detection of the peroxidaseconjugated secondary antibodies. For Coomassie blue Staining $10 \mu \mathrm{g}$ cytoplasmic and nuclear extracts were loaded on a 7\% SDS-PAGE gel. A prestained Standard (Bio-Rad Laboratories) was included in each run.

\section{Combined electrophoretic mobility shift assay (EMSA) and immunoblot}

Binding of extracted nuclear protein to a linear DNA probe was analysed as described in detail [18]. In brief, a double-stranded 25-mer DNA probe was prepared by two complementary oligonucleotides and T4 polynucleotide kinase (Roche-Boehringer-Mannheim) endlabeling. Closed circular pGEM plasmid DNA (Promega) was included in each assay as non-specific competitor in order to assay specifically for the binding of protein to free DNA ends. In some experiments cold probe was used as specific competitor, leading to loss of all gel shift bands. Nuclear protein extract was incubated with radiolabeled probes and the complete protease inhibitor, DTT, on ice for $20 \mathrm{~min}$. Reaction mixture was then loaded in duplicate onto a native $6 \%$ polyacrylamide gel (Invitrogen). After electrophoresis, one part of the gel was exposed to X-ray film to provide EMSA data. The remaining gel portion was blotted onto a PVDF membrane using a denaturing $\mathrm{pH} 8.0$ transfer buffer containing $0.5 \%$ SDS, $20 \%$ methanol, $20 \mathrm{mM}$ Tris and $150 \mathrm{mM}$ glycine. The membrane was incubated with anti-Ku70 and anti-Ku86, respectively, and subjected to the secondary peroxidase antibodies and developed as described in Western blot. The same membrane was used with a $2 \%$ SDSbuffer stripping step between these two $\mathrm{Ku}$ antibodies.

\section{Protease-resistant whole cell electrophoresis}

$5 \times 10^{5}$ cells for Ku86 assay or $1 \times 10^{6}$ cells for DNA-PKcs were washed with PBS and spinned down at $800 \mathrm{~g}$ for $3 \mathrm{~min}$. The cell pellet was subjected to one of three different preparation methods prior to loading on the SDS gel. With a standard SDS-PAGE whole cell protocol (referred to as method 1 in Fig. 5) sample buffer containing detergent $(4 \times \mathrm{NuPAGE}$ LDS Sample Buffer containing $8 \%$ LDS; final concentration $2 \%$, Invitrogen) and reducing agent (DTT, final concentration $50 \mathrm{mM}$ ) were added to the cell pellet just before a $10 \mathrm{~min}$ incubation at $99^{\circ} \mathrm{C}$. In a modified protocol (referred to as method 2 in Fig. 5), the cells were kept at $99^{\circ} \mathrm{C}$ for $5 \mathrm{~min}$ in the presence of DTT (50 $\mathrm{mM}$ ). Detergent (as above) was then added before another $5 \mathrm{~min}$ incubation at $99^{\circ} \mathrm{C}$. Another version (referred to as method 3 in Fig. 5) started with incubation at $99^{\circ} \mathrm{C}$ for $5 \mathrm{~min}$, then the LDS sample buffer (as above) and DTT were added before another incubation for $5 \mathrm{~min}$ at $99^{\circ} \mathrm{C}$. In order to demonstrate the reproducibility of the method samples were run on the gel in duplicate. Electrophoresis and immunoblotting were performed as described in Western blot.

\section{RESULTS}

Protein extracts reveal no signs of Ku or DNA-PKes in PMN, and presence of a truncated Ku86 variant form in HL-60

Cytoplasmic and nuclear protein fractions were extracted from the following cells: PMN, PBMC $0 \mathrm{~h}$ (isolated from freshly collected blood), PBMC $24 \mathrm{~h}$ (isolated from the same batch of blood incubated at room temperature for $24 \mathrm{~h}$ ), and the promyelocytic leukemia HL-60 and epithelial tumor HEp-2 cell lines. A monoclonal antibody to Nterminal Ku86 was used in order to detect both full-length and the C-terminally truncated variant form of Ku86 (Ku86v). Immunoblotting of cytoplasmic proteins showed intact $\mathrm{Ku} 86$ in all cell types except PMN (Fig. 1A). In addition, Ku86v was detected in PBMC $24 \mathrm{~h}$ and HL-60 (Fig. 1A, lanes 2 and 3). Nuclear extracts showed both intact and $\mathrm{Ku} 86 \mathrm{v}$ for PBMC $0 \mathrm{~h}$ and $\mathrm{HL}-60$, the degraded form in PBMC $24 \mathrm{~h}$, and only the full length form in HEp-2 (Fig. 1A). The higher 

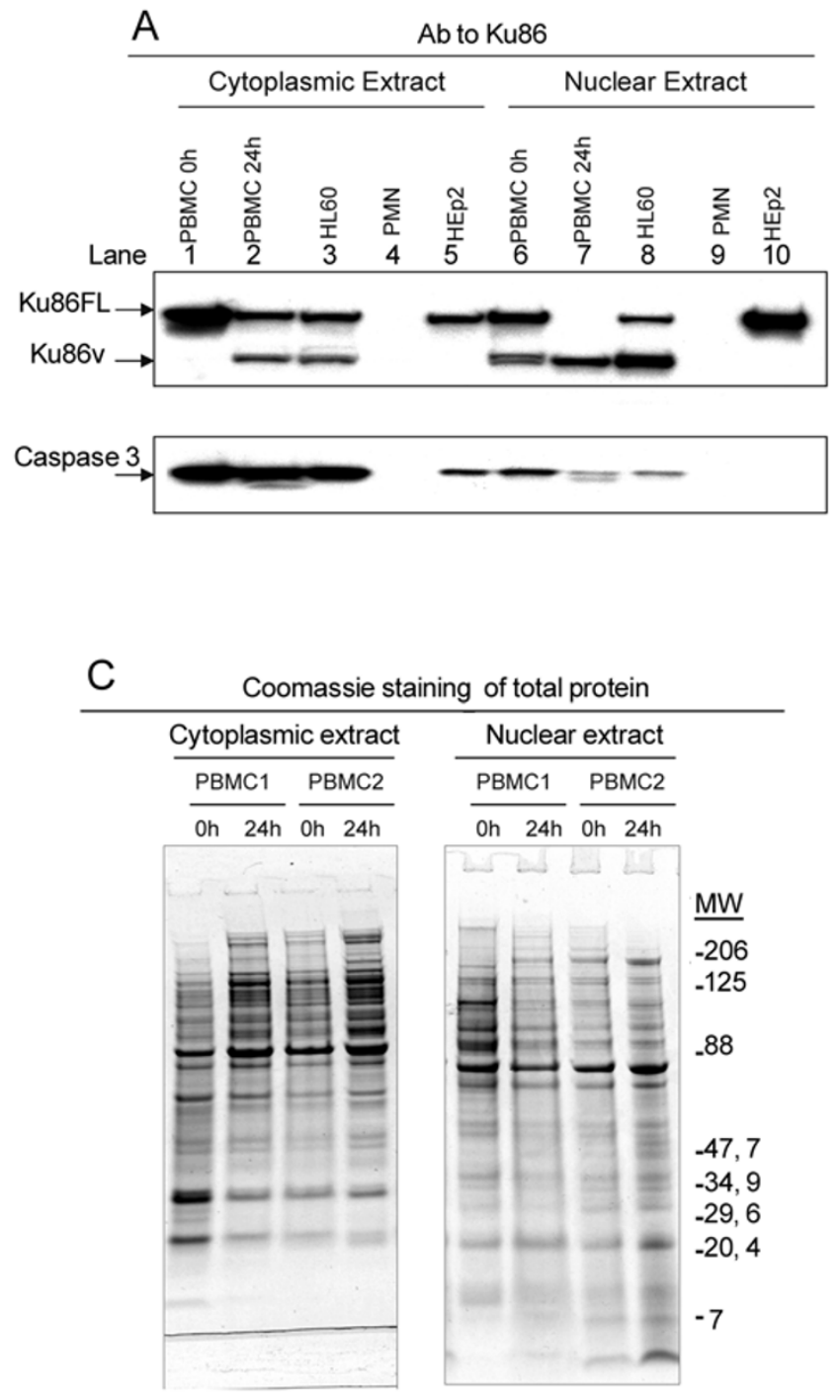

yield of degraded Ku86 in the nucleus, as compared with cytoplasm, is in agreement with previously published PBMC data $[18,19]$. DNA-PKcs was found in the extracts from PBMC 0 h, HL-60 and HEp-2, but not PBMC $24 \mathrm{~h}$ or PMN (Fig. 1B). Thus, no Ku86 or DNA-PKcs could be visualized in PMN extracts. Among the other cell types, the extent of Ku86 degradation correlated (inversely) with the level of DNA-PKcs. Not only DNA-PK was lacking in the PMN extracts, but also, as expected, a number of other proteins, including caspase 3 in nucleus and cytoplasm (Fig. 1A) and tubulin (restricted to cytoplasm) (Fig. 1B), as well as SS-A, SS-B and actin (data not shown). A weak tubulin reaction was occasionally noted in nuclear extracts (exemplified by HEp-2 in Fig. 1B). This illustrates the limitation of the employed cytoplasm/nucleus fractionation method; but also documents strong enrichment of nuclear

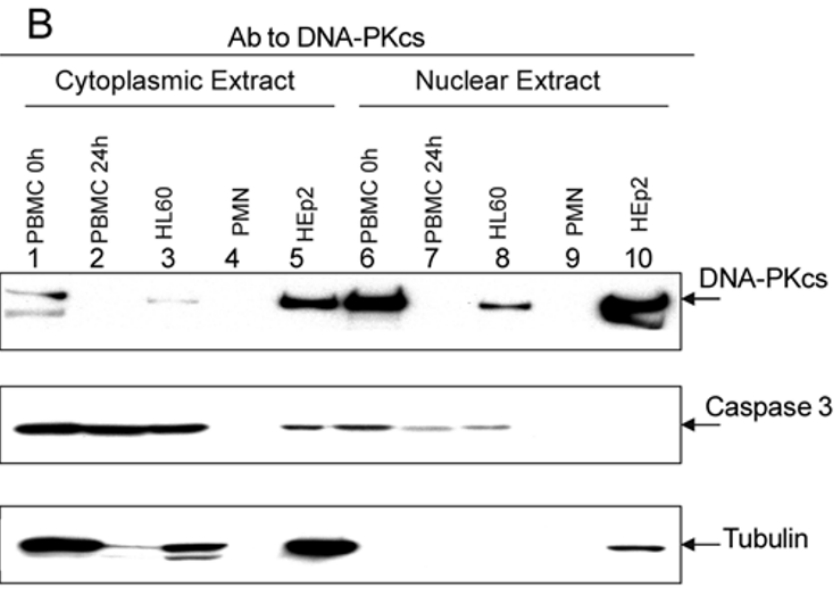

Fig. 1 Protein extracts reveal no signs of Ku or DNA-PKcs in $\mathrm{PMN}$, and presence of a truncated Ku86 variant form in HL-60. Western blot was performed using cytoplasmic and nuclear protein extracts of PBMC $0 \mathrm{~h}$ (isolated from fresh blood), PBMC $24 \mathrm{~h}$ (from blood stored for $24 \mathrm{~h}$ at room temperature), HL-60, PMN and HEp-2. Membranes were probed with N-terminal anti-Ku86 (A) and anti-DNA-PKes (B). The arrows indicate the positions of full length $\mathrm{Ku} 86(\mathrm{Ku} 86 \mathrm{FL})$, the approximately $70 \mathrm{kD} \mathrm{Ku} 86$ variant form (Ku86v) and intact $470 \mathrm{kD}$ DNA-PKcs. Caspase-3 and tubulin analysis were made using the same membranes, after a stripping procedure. Cytoplasmic and nuclear protein extracts obtained from two blood donors were electrophoresed and stained with Coomasssie blue (C).

proteins in the nuclear extract. The $32 \mathrm{kD}$ proform of caspase 3 was seen, with no evidence of the active $17 \mathrm{kD}$ cleavage derivative. Caspase 3 and cytoskeleton components were chosen as control proteins, since they can be assumed to be present in intact PMN, therefore, these negative findings verify a general proteolysis during PMN protein extraction, even though with the presence of potent protease inhibitors. Caspase 3 nuclear extract band intensity was lower in PBMC $24 \mathrm{~h}$ and HL-60 (Fig. 1A-B, lanes 7-8), as compared with PBMC $0 \mathrm{~h}$, indicating protein degradation also in these cell extracts. Tubulin was more protease-sensitive than caspase 3 , as judged by weak bands in the PBMC $24 \mathrm{~h}$ and HL-60 cytoplasmic extracts (lanes 2-3). Total protein was determined by Coomassie blue staining in the PBMC $0 \mathrm{~h}$ and PBMC $24 \mathrm{~h}$ extracts, obtained from two separate donors, with strong signs of 
DNA-PK degradation at $24 \mathrm{~h}$. The resulting banding pattern revealed most proteins remain intact at $24 \mathrm{~h}$, with the possible exception of some high molecular weight $(>200 \mathrm{kD})$ bands in the nuclear extracts (Fig. 1C). This indicates that Ku86v and degraded DNA-PKcs arise as part of action on a minor subset of the total cellular protein. The combined results of Fig. 1 clearly show the deficiency of cell extracts for analysis of PMN proteins, due to extensive protein degradation.

\section{A protease in PMN and HL-60 protein extracts de- grades Ku86 and DNA-PKes}

PMN and HEp-2 protein extracts were mixed and coincubated in order to assay for protease in PMN acting on the DNA-PK of HEp-2. Incubation-dependent degradation of Ku86 occurred rapidly, and become virtually complete within $30 \mathrm{~min}$ at $37^{\circ} \mathrm{C}$ (Fig. 2A). Mixing of cytoplasmic extracts revealed less intense signs of Ku86 degradation (not shown). HEp-2 protein extract alone showed no detectable Ku 86 variant form even after $1 \mathrm{~h}$ incubation at $37^{\circ} \mathrm{C}$ (Fig. 2A, lane 1), indicating that PMN is the source of the protease activity. The level of DNA-PKcs was similarly decreased for the incutated mixture of nuclear extracts (Fig. 2B). Titration of the PMN extract, down to ten-fold less than in Fig. 1A-B, also revealed signs of degradation of HEp-2 and DNA-PKcs (results not shown). The same mixing was also applied to extracts from HL-60 and HEp- 2 cells, revealing the presence of a Ku86- and DNA-PKcs-degrading protease in HL-60 nuclear extracts (Fig. 2C-D, lanes 1-5). The activity of degrading protease was lower in the cytoplasmic extracts (only Ku86 was assayed, Fig. 2C, lanes 6-10). This proteolytic activity was much weaker in HL-60, as compared with PMN, with full length $\mathrm{Ku} 86$ still present after $1 \mathrm{~h}$ incubation at $37^{\circ} \mathrm{C}$ (Fig. $2 \mathrm{C}$, lane 5 ). In order to facilitate a comparison between the DNA-PK-degrading protease activities in the different cell types, protein extracts from PBMC, HL-60 and PMN, respectively, were co-incubated with a HEp-2 extract. Some degradation of the HEp-2 Ku86 could be seen in all of these extracts after $15 \mathrm{~min}$ at $37^{\circ} \mathrm{C}$ (Fig. 2E). The fingerprint banding profile reflecting several forms of highly degraded Ku86 was virtually identical among these cell types (Fig. 2E, lanes 2-4), indicating a similarity between all these protease activities.

\section{DNA-binding of both intact Ku86 and a truncated variant form in HL-60 nuclear protein extracts}

In order to assess the functional consequences of Ku86 degradation, the DNA end-binding activity of Ku86 was studied using an electrophoretic mobility shift assay (EMSA) together with immunoblotting. A radiolabeled blunt-ended DNA fragment was incubated with nuclear protein extract obtained from HEp-2, PBMC, PMN, HL-60, K562, U937 and NB-4 leukemia lines. This mixture was then electrophoresed on a duplicate native gel, one part of the gel for EMSA and the other for immunoblotting. EMSA showed differences in DNA end-binding activity among these cell types, with two DNA-binding complexes for HEp-2, and an additional middle gel shift complex for PBMC $0 \mathrm{~h}$ and HL-60 (Fig. 3A). The intensity of the upper complex in EMSA was nearly the same for PBMC $0 \mathrm{~h}$ and HEp-2, but weaker for HL-60. The intensity of the middle complex was almost identical for PBMC $0 \mathrm{~h}$ and HL-60. No apparent DNA-binding activity in PMN extracts could be detected. The EMSA-pattern of the other leukemia lines studied (promyelocytic NB-4, erythroleukemia K562 and monocytic U937) was similar to that of HEp-2, with none of them displaying the middle-type band of HL-60 and PBMC $0 \mathrm{~h}$.

Immunoblotting of the duplicate gel with both anti-Ku70 and anti-Ku86, respectively, showed two bands for PBMC $0 \mathrm{~h}$ and HL-60, but only one band for HEp-2 and other leukemia lines (Fig. 3B). The presence of both $\mathrm{Ku} 70$ and $\mathrm{Ku} 86$ bands in positions corresponding to the upper and middle DNA-binding complexes in EMSA indicates that binding of $\mathrm{Ku}$ to DNA ends occurs to heterodimeric $\mathrm{Ku}$ $70 / 86$, and that a truncated Ku86 form still retains DNAbinding activity. The intensity of the bands in immunoblotting correlates with that of the EMSA DNA-binding complexes, i.e. HL-60 shows strong middle gel shift DNA-binding complex and strong lower immunoblotting band; whereas PBMC $0 \mathrm{~h}$ shows a strong upper EMSA band and a strong upper immunoblotting band. The relatively weak DNA binding in HL-60 of heterodimeric full length $\mathrm{Ku} 70$ and $\mathrm{Ku} 86$ (upper band in Fig. 3B) is compatible with a dominant negative influence by degraded Ku86 in HL-60, as suggested by Han et al [12]. There was no $\mathrm{Ku}$ band corresponding to the lower gel shift DNA-binding complex in EMSA. Repeated EMSA-immunoblotting using antibodies to $\mathrm{Ku} 86, \mathrm{Ku} 70$, DNA-PKcs and DNA ligase IV revealed no detectable band corresponding to this position in EMSA (not shown). In summary, our data verified that the proteolytic degradation of Ku86 is associated with an altered DNA-binding pattern in HL-60 cells.

\section{Contamination with PMN is strongly linked to DNA- $P K$ degradation in PBMC preparations}

The finding of a potent protease activity in PMN extracts raised the question whether low-grade contamination with PMN in PBMC preparations significantly contributes to the Ku86- and DNA-PKcs-degradation seen in PBMC protein extracts. The storage of blood for $24 \mathrm{~h}$ did not significantly alter the percentages of PMN, monocytes and lymphocytes; there was a tendency for a lower fraction 
A

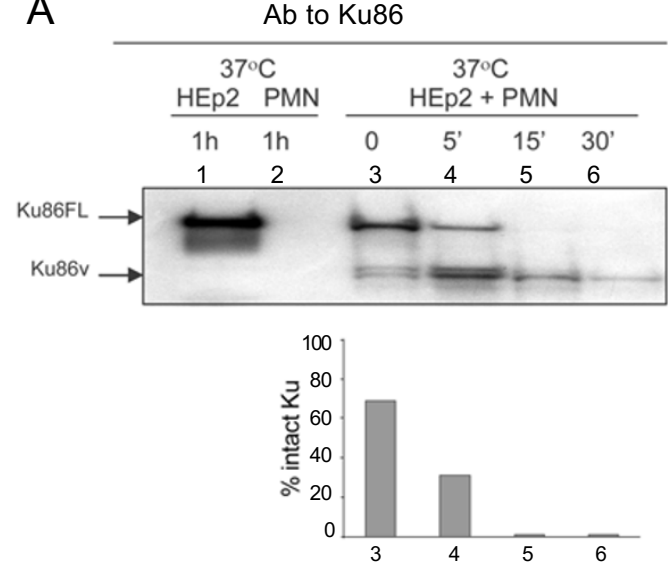

C

Ab to Ku86
B
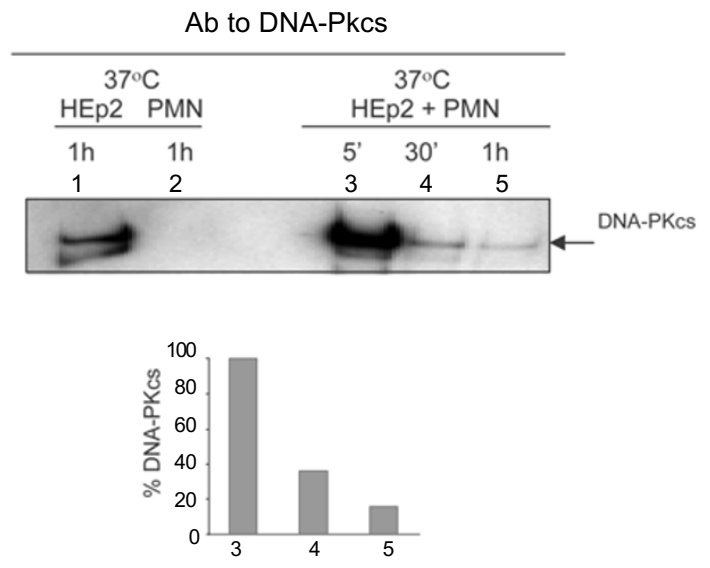

$\mathrm{D}$

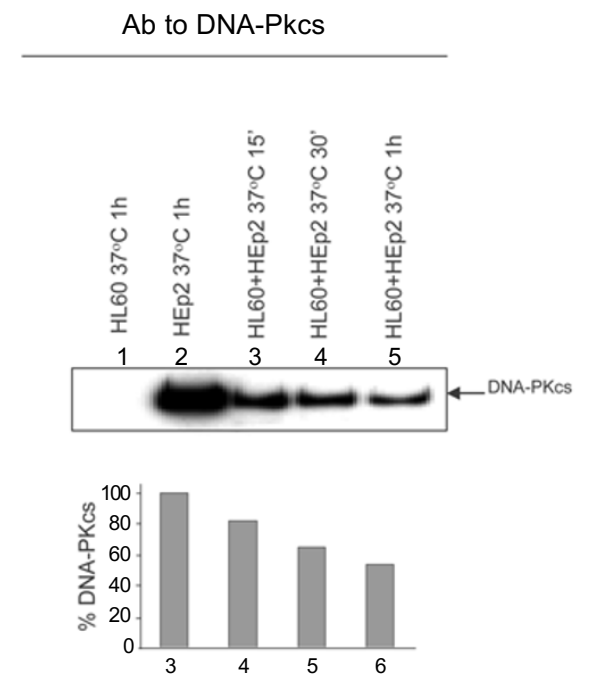

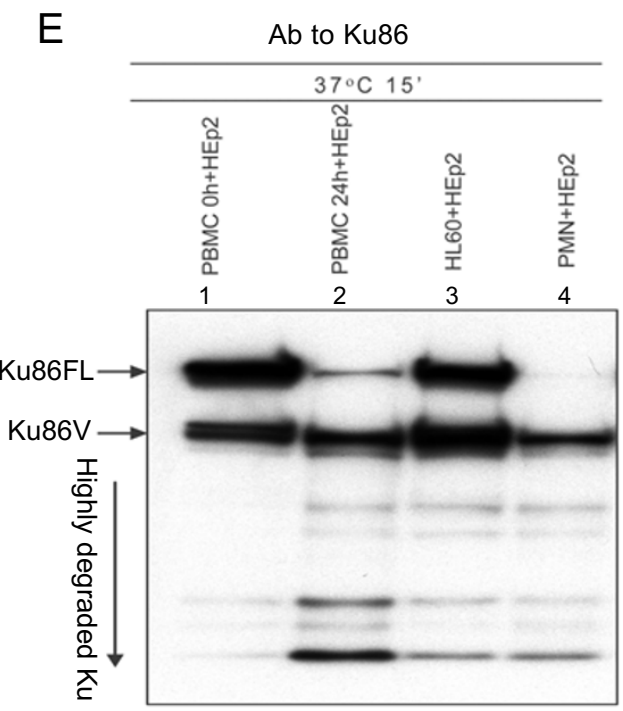

Fig. 2 A protease in PMN and HL-60 protein extracts degrades Ku86 and DNA-PKcs. Nuclear protein extracts from HEp-2 and PMN (A and B), and from HEp-2 and HL-60 (C and D), were mixed and co-incubated at $37^{\circ} \mathrm{C}$, and then analysed by Western blot with N-terminal anti-Ku86 (A and C) and anti-DNA-PKcs (B and D). $5 \mu \mathrm{g}$ nuclear protein from PMN and $2.5 \mu \mathrm{g}$ from HEp-2 were used for Ku86; $10 \mu \mathrm{g}$ from both cell types for DNA-PKcs; the same amounts were used in the single extract incubations (Fig 2A-D, lanes 1 and 2; Fig 2C, lanes 6 and 7). The staples illustrate: (A and C), the relative amount of the intact $\mathrm{Ku} 86 \mathrm{FL}$ form (in relation to the sum of Ku86FL and Ku86v); (B and D), the amount of DNA-PKcs, with the level in lane 3 (B) and lane 2 (D) normalized to $100 \%$. (E); nuclear protein extracts from PBMC 0h, PBMC 24h, HL-60 and PMN were assayed for Ku86-degrading protease activity by coincubation with HEp-2 extract, and then analysed by Western blot in order to facilitate a comparison of the resulting band profiles. The arrows indicate the positions of $\mathrm{Ku} 86 \mathrm{FL}, \mathrm{Ku} 86 \mathrm{v}$ and highly degraded Ku86. 

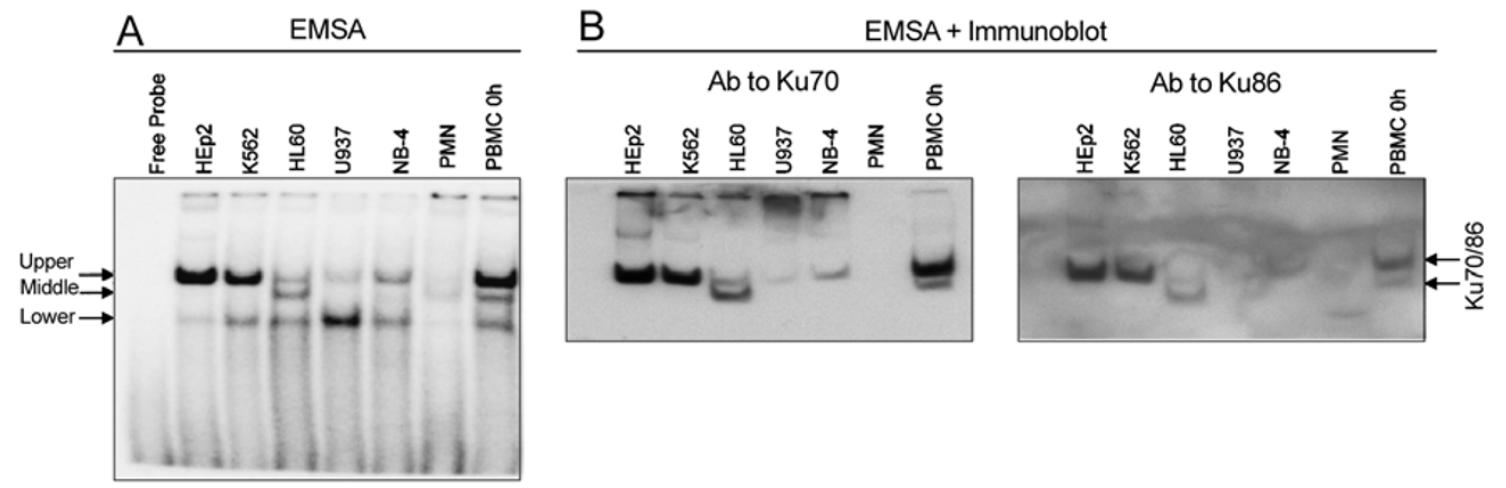

Fig. 3 DNA-binding of both intact Ku86 and a truncated variant form in HL-60. Nuclear protein extracts from the indicated cell types were analysed for protein-binding to the free ends of a radiolabeled 25-mer double-stranded DNA fragment. A duplicate native polyacrylamide gel was run; with one part for EMSA (A) and the other for Ku70 and Ku86 immunoblotting (B). The arrows in (A) indicate the resulting DNA-protein complexes, and in (B) the positions of binding of anti-Ku70 and anti-Ku86. In order to obtain optimal separation of the three binding complexes, electrophoresis time was extended causing most of the free probe to leave the gel, but some activity can be seen at the gel bottom (A).

of monocytes at $24 \mathrm{~h}$ as compared to freshly isolated $0 \mathrm{~h}$ cells. However, among the density gradient-isolated cells assumed to contain only mononuclear cells, flow cytometry analysis revealed a consistently higher PMN fraction for PBMC 24h (1.8-8.8\% of the cells being PMN), as compared with PBMC 0h (0.5-1.0\% PMN) (Fig. 4A). This increased PMN fraction may be due to granule changes, leading to a PMN density approaching that of PBMC. Trypan blue dye exclusion revealed less than $1 \%$ dead cells in these PBMC preparations (data not shown). A strong correlation was seen between the percentage of PMN contaminants and the degradation of Ku86 (Fig. 4B) and DNA-PKes (Fig. 4C) in the corresponding PBMC nuclear protein extracts. The level of caspase 3 was affected, although in less extent by the increased PMN fraction (Fig. 4B-C). The combined results of Fig. 4 suggest that most of the DNA-PK degradation observed in PBMC is due to contaminating PMN. Whether some minor DNA-PK degradation occurs in PBMC per se as well remains to be determined.

\section{Protease-resistant whole cell assay apparently elimi- nates protein degradation caused by PMN proteases}

In search of protease activity exerted in vivo, we developed a protease-resistant whole cell electrophoresis assay. We then reasoned that there is an opportunity for protein degradation during the short time interval positioned between diffusion out of granules and efficient action by the added protease inhibitors. Therefore, the cytotoxic proteases stored in PMN granules need to be inhibited before their releasing into the cytosol [19]. We tested whether this could be accomplished by a freely diffusible reducing agent such as DTT, or by heat treatment inserted before exposure of the cells to detergent. Three preparation methods were tested. PMN were isolated from two blood donors, denoted as PMN1 and PMN2 in Fig. 5A. Using a standard protocol (method 1, with sample buffer containing detergent) the PMN showed a faint Ku86 band, and a weak actin band (Fig. 5A, method 1), whereas clearly stronger Ku 86 and actin signals were obtained with the methods 2 and 3, exposing the PMN to DTT and heat, respectively, before the addition of detergent (Fig. 5A, methods 2-3). The same methods 1-3 were tested also with HL-60 (Fig. 5B-C). Identical and strong evidence of Ku86 was found for all three treatments (Fig. 5B), while method 1 showed a lower level of DNA-PKcs, as compared with the other treatment types (Fig. 5C). Thus, whole cell analysis with reducing agent or heat prior to detergent made it possible to detect intact PMN proteins.

\section{Presence of both Ku86 and DNA-PKes at low con- centrations in PMN, and at an elevated level in HL-60}

A whole cell electrophoresis protocol apparently eliminating influence of PMN proteases (utilising the preparation method referred to as type 3 in Fig. 5, with an initial heat treatment before the addition of any detergent) was used for semi-quantitation of DNA-PK. Full length Ku86 could be demonstrated in PBMC 0 h, PBMC 24 h, PMN and HL-60, with the lowest band intensity for PMN (Fig. $6 \mathrm{~A}$, lanes 5 and 6). Interestingly, HL-60 showed clearly stronger band intensities for both Ku86 and DNA-PKcs, as compared with PBMC (Fig. 6A-B, lanes 7 and 8), whereas the protein extract from HL-60 suggested a rela- 
A

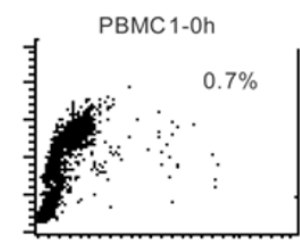

PBMC2-0h

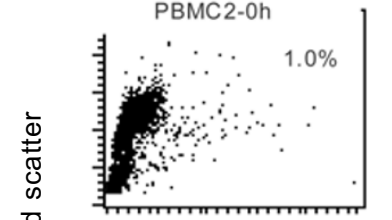

PBMC3-0h

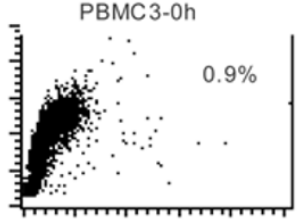

PBMC4-0h

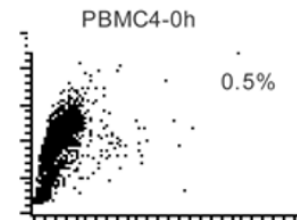

Side scatter

C

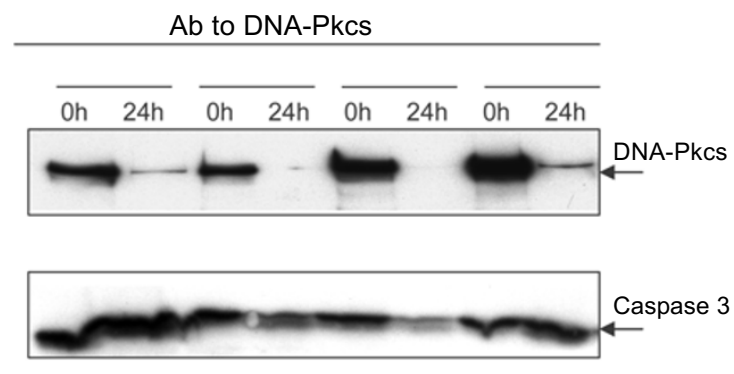

B
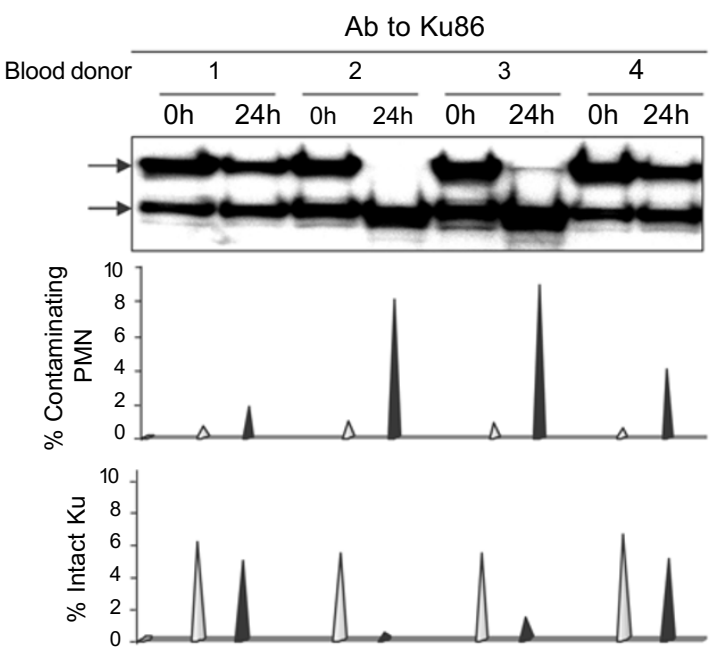

Caspase 3

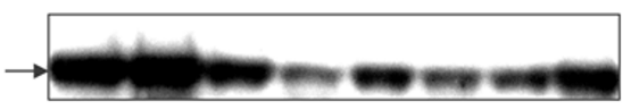

Fig. 4 Contamination with PMN is strongly linked to DNA-PKdegradation in PBMC preparations. PBMC were isolated from fresh blood (PBMC 0h) and $24 \mathrm{~h}$ incubated blood (PBMC $24 \mathrm{~h}$ ); from four blood donors (denoted as PBMC1-4). The fraction of contaminating PMN was determined by flow cytometry. The indicated percentage refers to PMN population positive in both side- and forward scatter (A) Western blot was then performed with nuclear protein extracts from all of these PBMC preparations, using Nterminal anti-Ku86 (B) and anti-DNA-PKcs $(\mathbf{C})$. The upper cone panel illustrate the $\%$ contaminating PMN, and the lower cone panel the relative amount of the intact $\mathrm{Ku} 86$ form (in relation to the sum of $\mathrm{Ku} 86 \mathrm{FL}$ and $\mathrm{Ku} 86 \mathrm{v}$ ); open cones, PBMC $0 \mathrm{~h}$; filled cones, PBMC $24 \mathrm{~h}$. Caspase 3 analysis was performed using the same membrane after a stripping procedure.

tively low level of full length Ku 86 and DNA-PKcs (Fig. 1A-B). HL-60, as well as PBMC and PMN, presented no clear evidence of Ku86v, putting any physiological function of truncated Ku86 into question. Using the same number of cells $\left(5 \times 10^{5}\right)$, no DNA-PK could be visualized in PMN (Fig. 6B, lanes 5-6). However, when the number of cells doubled, the expression band of DNA-PKcs became apparent also for PMN (Fig. 6D). A set of control experiments were done, in order to document that the observation of Ku86 and DNA-PKcs in PMN is not due to the contaminating PBMC. The PMN preparations in Fig. $6 \mathrm{C}$, obtained from 4 blood donors, contained $3 \%$ and $2 \%$ PBMC (C), and 5\% for that of Fig. D, as determined by flow cytometry (not shown). The band intensity resulting from the corresponding numbers of contaminating PBMC were clearly weaker than the bands of the PMN preparations (Fig. 6C-D). This verifies that the Ku86 and DNA-PKcs signals in PMN are not due to contaminating PBMC, and that PMN indeed contain both Ku86 and DNAPKcs. Analysis of actin verified the loading of the cell numbers (Fig. 6A-D). The combined results of Fig. 5-6 with clearly weaker DNA-PK band intensities in PMN, as compared with that in PBMC, strongly indicates that PMN contain reduced concentrations of both Ku86 and DNA-PKcs. In contrast, HL-60 displays elevated levels of both of these DNA repair proteins; this is particularly marked for DNA-PKes (Fig. 6 B and D).

\section{DISCUSSION}

A truncated form of $\mathrm{Ku} 86$ has been demonstrated in protein extracts from human $\mathrm{T}$ and $\mathrm{B}$ lymphocytes [18, 20-22], senescent fibroblasts [23], HL-60 [12], and from 
A

Ab to Ku86

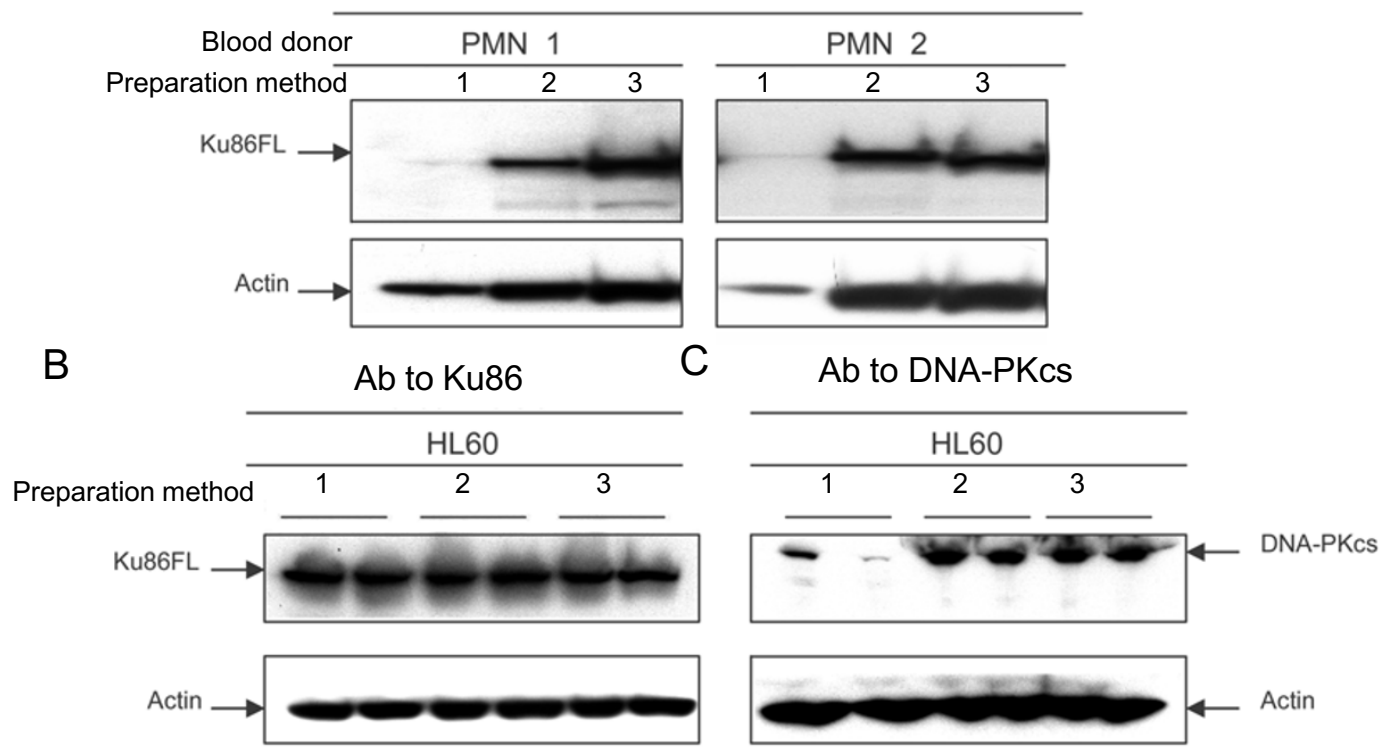

Fig. 5 Protease-resistant whole cell assay apparently eliminates protein degradation caused by PMN proteases. $5 \times 10^{5}$ cells were used for analysis of Ku86 (A and B) and $1 \times 10^{6}$ cells for DNA-PKcs (C). Cells were treated in 3 different ways prior to loading onto the gel. These preparation methods are indicated as 1, 2 and 3. In method 1, cells were heat-treated in the presence of detergent and DTT. In method 2, cells were heat-treated with DTT only, and detergent was added $5 \mathrm{~min}$ later. In method 3, cells were heated for $5 \mathrm{~min}$ before addition of both detergent and DTT. Western blot was performed with N-terminal anti-Ku86 (A and B) and anti DNA-PKcs (C). PMN1 and PMN2 refer to two different blood donors. The same membrane was used for actin analysis after a stripping procedure.

A

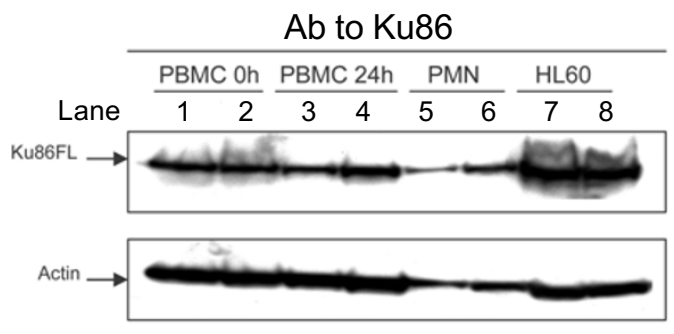

C

Ab to Ku86

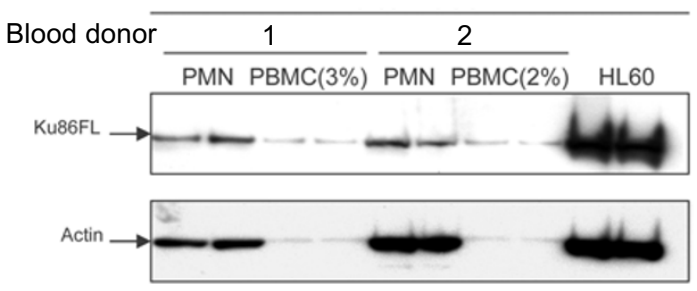

B

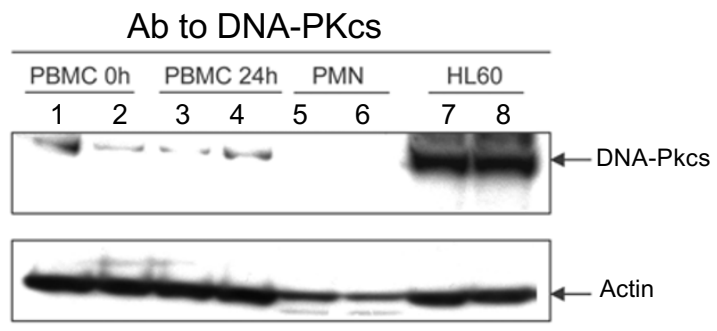

D

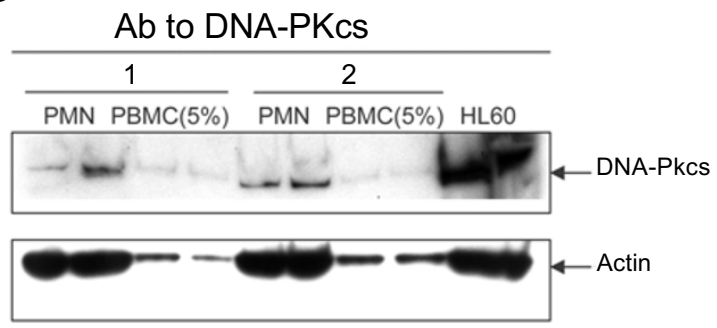

Fig. 6 Concentrantion of both Ku86 and DNA-PKes was low for PMN, and elevated for HL-60. $5 \times 10^{5}$ (A-C) and $1 \times 10^{6}($ D) cells were heat-treated prior to the addition of sample buffer and DTT (method type 3 in Fig 5). All samples were run in duplicate adjacent wells. Western blotting was performed using N-terminal anti-Ku86 (A and C) and anti-DNA-PKcs (B and D). The indicated percentages of contaminating PBMC in PMN preparations were determined by flow cytometry. PBMC and PMN were isolated from the same blood portion. Actin content was determined after membrane stripping. 
freshly obtained samples of lymphoid malignancies including chronic lymphocytic leukemia and multiple myeloma $[24,25]$. However, the clinical relevance of this Ku86 variant form remains controversial, since, in studies on lymphocytes and fibroblasts, it has been shown to be formed during the experimental procedure of protein extraction. Furthermore, rapid lysis of whole cells immediately prior to SDS gel electrophoresis revealed no signs of Ku86 truncation [19, 22, 23]. Per-experimental induction of the Ku86 variant form in multiple myeloma was also suggested by a study unable to demonstrate any degraded form of $\mathrm{Ku}$ in this tumor type [26].

We now report the presence of a proteolytic activity capable of degrading both Ku86 and DNA-PKes, in the pro-granulocytic HL-60 cell line and in terminally differentiated PMN. It may seem hard to conceive that Ku86 and DNA-PKcs should be targeted by the same protease. However, the amino acid sequence analysis reveals $\mathrm{C}$-terminally located arginine/lysine rich sites in both proteins, which may be recognized by the DNA-PK-degrading trypsin-like serine protease reported earlier [18]. To what extent can this DNA-PK-degrading protease be assumed to contribute to the in vivo low levels of Ku86 and DNAPKcs in PMN? Down-regulation of DNA-PKcs gene expression has been demonstrated in PMN and also in some cases of human AML [16]. However, due to the long halflife of Ku86 and DNA-PKcs in myeloid cells (K562), mRNA reduction has been demonstrated to be not sufficient to give the observed deficiency in DNA-PK [3]. It was therefore suggested that a mechanism for elimination of DNA-PK is operating in human PMN [3]. Such a concept of elimination of DNA-PK eventually leading to a reduced protein level after many cell generations, fits well with our combined observation of decreased DNA-PK concentration in PMN, together with a DNA-PK degrading protease. Interestingly, our finding of a high in vivo content of DNAPK in HL-60, as compared with PBMC (Fig. 6) adds weight to this argument: a strong reduction of DNA-PK is then needed during the ensuing differentiation to attain the low DNA-PK level seen in mature PMN. Besides proteolysis and gene repression, additional mechanisms have been demonstrated for the regulation of DNA-PK activity, which may also fit well in PMN [5, 27, 28]. These include the inhibition of DNA-binding caused by oxidation of $\mathrm{Ku}$ cystein residues, which seems particularly relevant to ROS-producing myeloid cells [29].

Our results are consistent with a prevailing view of down-regulation of DNA repair in terminally differentiated $[30,31]$ and in apoptosis-destined cells [32]. These cells are non-dividing, and DNA damage may therefore be of little genetic consequence. Such cells need to make some kind of cost-benefit decision, in order to focus on a main task. The cost of maintaining genetic integrity can be assumed to be unusually high for a PMN, because of the endogenous DNA single- and double-strand breaks in PMN resulting from large-scale ROS production $[9,33]$. The microbicidal task of the terminally differentiated PMN is very specialized, requiring much ATP and posing a limited demand for intact DNA sequence and DNA repair [30]. Even if NHEJ per se consumes relatively little ATP, as compared to e.g. polyadenylation elicited by DNA strand breaks, DNA damage responses mediated by DNA-PKcs include a cascade of events such as p53 activation [5,34]. Approaching the highly energy-demanding apoptosis phase including DNA fragmentation might also motivate the PMN not to invest its ATP in DNA repair. Unless a DNA damage response is inhibited, an energy catastrophy and necrosis, instead of apoptosis, may ensue $[30,35]$.

\section{ACKNOWLEDGEMENTS}

This work was supported by the Swedish Institute, the Swedish Cancer Society, Malmo General Hospital Cancer Fund, and by the Crafoord, Alfred Österlund, Gunnar Nilsson, Kocks and Gustaf Vs 80arsfond Foundations.

Received, Feb 13, 2004

Revised, Jun 3, 2004

Accepted, Jun 6, 2004

\section{REFERENCES}

1 Terai C, Wasson DB, Carrera CJ, Carson DA. Dependence of cell survival on DNA repair in human mononuclear phagocytes. J Immunol 1991; 147:4302-6.

2 Lankinen MH, Vilpo LM, Vilpo JA. UV- and gamma-irradiationinduced DNA single-strand breaks and their repair in human blood granulocytes and lymphocytes. Mutat Res 1996; 352:31-8.

3 Ajmani AK, Satoh M, Reap E, Cohen PL, Reeves WH. Absence of autoantigen $\mathrm{Ku}$ in mature human neutrophils and human promyelocytic leukemia line (HL-60) cells and lymphocytes undergoing apoptosis. J Exp Med 1995; 181:2049-58.

4 Sanghavi DM, Thelen M, Thornberry NA, Casciola-Rosen L, Rosen A. Caspase-mediated proteolysis during apoptosis: insights from apoptotic neutrophils. FEBS Letters 1998; 422:179-84.

5 Smith GCM, Jackson SP. The DNA-dependent protein kinase. Genes Devel 1999; 13:916-34.

6 Eriksson A, Lewensohn R, Nilsson A. Expression and activity of DNA-dependent protein kinase in normal human leukocytes. Anticancer Res 2000; 20:3051-8.

7 Choi ÉK, Lee YH, Choi YS, et al. Heterogeneous expression of $\mathrm{Ku} 70$ in human tissues is associated with morphological and functional alterations of the nucleus. J Pathol 2002; 198:121-30.

8 Kurozawa A, Shinohara K, Watanabe F, et al. Human neutrophils isolated from peripheral blood contain $\mathrm{Ku}$ protein but not DNA-dependent protein kinase. Int J Biochem Cell Biol 2003; 35:86-94

9 Vilenchik MM, Knudson AG. Endogenous DNA double-strand 
breaks: Production, fidelity of repair, and induction of cancer. PNAS 2003; 100:12871-6.

10 Abbas AK, Lichtman AH. Eds. Molecular and Cellular Immunology. (4th ed.) WB Saunders Philadelphia 2003:274.

11 Yaneva M, Jhiang S. Expression of the Ku protein during cell proliferation. Biochim. Biophys. Acta 1991; 1090:181-7.

12 Han Z, Johnston C, Reeves WH, et al. Characterization of a $\mathrm{Ku} 86$ variant protein that results in altered DNA binding and diminished DNA-dependent protein kinase activity. J Biol Chem 1996; 271:14098-104.

13 Shen H, Schultz M, Krub GD, Tew KD. Increased expression of DNA-dependent protein kinase confers resistance to adriamycin. Biochim. Biophys. Acta 1998; 1381:131-8.

14 Muller C, Monferran S, Gamp AC, Calsou P, Salles B. Inhibition of Ku heterodimer DNA end binding activity during granulocytic differentiation of human promyelocytic cell lines. Oncogene 2001; 20:4373-82.

15 Gaymes TJ, Mufti GJ, Rassool FV. Myeloid leukemias have increased activity of the nonhomologous end-joining pathway and concomitant DNA misrepair that is dependent on the $\mathrm{Ku} 70$ / 86 heterodimer. Cancer Res 2002; 62:2791-7.

16 Alcalay M, Meani N, Gelmetti V, Fantozzi A, et al. Acute myeloid leukemia fusion proeins deregulate genes involved in stem cell maintenance and DNA repair. J Clin Invest 2003; 112:1751-61.

17 Sallmyr A, Henriksson G, Fukushima S, Bredberg A. Ku protein in human T and B lymphocytes: full length functional form and signs of degradation. Biochim. Biophys. Acta 2001; 1538:305-12.

18 A Sallmyr, L Du, A Bredberg. An inducible Ku86-degrading serine protease in human cells. Biochim. Biophys. Acta 2002; 1593:57-68.

19 Alberts B, Johnson A, Lewis J, et al. Molecular Biology of the Cell (Fourth Edition) Garland Science Taylor \& Francis Group, New York 2002:Chapter 8 and page 668 .

20 Muller C, Dusseau C, Calsou P, Salles B. Human normal peripheral blood B-lymphocytes are deficient in DNA-dependent protein kinase activity due to the expression of a variant form of the Ku86 protein. Oncogene 1998; 16:1553-60.

21 Morio T, Hanissian SH, Bacharier LB, et al. Ku in the cytoplasm associates with CD40 in human B cells and translocates into the nucleus following incubation with IL-4 and anti-CD40 mAb. Immunity 1999; 11:339-48.

22 Vral A, Thierens H, Bryant P, Ridder De L. A higher micro- nucleus yield in B- versus T-cells after low-dose gamma-irradiation is not linked with defective Ku86 protein. Int J Radiat Biol 2001; 77:329-39.

23 Jeng YW, Chao HC, Chiu CF, Chou WG. Senescent human fibroblasts have elevated $\mathrm{Ku} 86$ proteolytic cleavage activity. Mutat Res 1999; 435:225-32.

24 C Muller, B Salles. Regulation of DNA-dependent protein kinase activity in leukemic cells. Oncogene 1997; 15:2343-8.

25 Tai YT, Teoh G, Lin B, Davies FE, et al. Ku86 variant expression and function in multiple myeloma cells is associated with increased sensitivity to DNA damage. J Immunol 2000; 165:6347-55.

26 Kato M, Iida S, Komatsu H, Ueda R. Lack of Ku80 alteration in multiple myeloma. Jpn J Cancer Res 2002; 93:359-62.

27 Myung K, He DM, Lee SE, Hendrickson EA. KARP-1: a novel leucine zipper protein expressed from the Ku86 autoantigen locus is implicated in the control of DNA-dependent protein kinase activity. EMBO J 1997; 16:3172-84.

28 Yang J, Yu Y, Duerksen-Hughes PJ. Protein kinases and their involvement in the cellular response to genotoxic stress. Mutat Res 2003; 543:31-58.

29 Ayene IS, Stamato TD, Mauldin SK, et al. Mutation in the glucose-6-phosphate dehydrogenase gene leads to inactivation of $\mathrm{Ku}$ DNA end binding during oxidative stress. J Biol Chem 2002; 277:9929-35.

30 Nouspikel T, Hanawalt PC. DNA repair in terminally differentiated cells. DNA Repair 2002; 1:59-75.

31 Spivak G, Lloyd RS, Sweder KS. Workshop on DNA repair and related DNA translations, a conference report. DNA Repair 2003; 2:235-42.

32 Bernstein C, Bernstein H, Payne CM, Garewal H. DNA repair/ pro-apoptotic dual-role proteins in five major DNA repair pathways: fail-safe protection against carcinogenesis. Mutat Res 2002; 511:145-78.

33 Birnboim HC, Sandhu JK. Levels of DNA strand breaks and superoxide in phorbol ester-treated human granulocytes. J Cell Biochem 1997; 66:219-28.

34 de Murcia G, Shall S. Eds. From DNA damage and stress signalling to cell death Poly ADP-ribosylation reactions. Oxford University Press, New York 2000.

35 Martinou JC, Green DR. Breaking the mitochondrial barrier. Nat Rev Mol Cell Biol 2001; 2:63-7. 